\title{
Thriving Products Designed to Fill Uganda's Market Loopholes
}

\author{
Juliet Kategaya Nsiima, Xing Fang, Jiefeng Lv \\ School of Art and Design, Wuhan University of Technology, Wuhan, China \\ Email: jnsiima@gmail.com
}

How to cite this paper: Nsiima, J.K., Fang, X. and Lv, J.F. (2019) Thriving Products Designed to Fill Uganda's Market Loopholes. American Journal of Industrial and Business Management, 9, 904-913. https://doi.org/10.4236/ajibm.2019.94062

Received: March 17, 2019

Accepted: April 15, 2019

Published: April 18, 2019

Copyright $\odot 2019$ by author(s) and Scientific Research Publishing Inc. This work is licensed under the Creative Commons Attribution International License (CC BY 4.0).

http://creativecommons.org/licenses/by/4.0/ (c) (i) Open Access

\begin{abstract}
The Ugandan market has recently thrived from products designed for local population consumption. They have also strengthened the economy and protected the environment. These products are designed by innovators, inventors and companies that identify and fill loopholes in various market sectors that Western and Asian suppliers have not penetrated. The youth in Uganda is a catalyst for local and foreign innovators and investors wanting to design and distribute products that will improve their livelihoods and the economy at large. In this paper, four innovative products that are thriving in the Ugandan market will be studied. One futuristic product will also be mentioned. They provide answers to Uganda's economic challenges ranging from energy crisis, poor or no transportation, access to hygiene/health and education services and "miseducation" and how these products are being designed to give solutions.
\end{abstract}

\section{Keywords}

Ugandan Market, Youth, Product Design, Innovation, Technology

\section{Introduction}

Uganda's current population is approximately 43.5 million with $80 \%$ under the age of 20 years whereby ages 0 - 15 years are $49.9 \%$ of the population. The young population of $0-15$ years has a dependency ratio of approximately $104 \%$, putting a heavy strain on the productive age group of 25 - 64 years. This pressure has made innovators, inventors and companies think of pragmatic solutions especially in the capital city, Kampala and major towns. Being a third world country, Uganda has budding or mismanaged public structures and systems that urgently need to develop. The Ugandan youth are a major influence in the growth of Uganda's economy because they have the numbers, the raw talent and oppor- 
tunities to grow the market economy (Figure 1).

This is a stark contrast to Chinese and Western populations whereby people of ages 25 - 64 years are the majority at $73.6 \%$ and are therefore able to support the young and the elderly groups. Though China is a second world country (58\% of its population is rural), it has more strengths than Uganda but it is not as advanced as developed countries (Figure 2).

\section{Research Method}

This will be a qualitative research study whereby I will highlight how successful products that are designed to solve some of Uganda's young population's challenges. This qualitative method will also give insight into Uganda's bottlenecks hindering the evolution and growth of product design today. Finally, I will suggest solutions to some of the bottlenecks and make a comprehensive conclusion on the way forward. Hopefully, findings from this paper will instigate further research into how to create better and more local product designs than seeking international intervention.

\section{Achievements in Product Design}

Achievements in some product designs in the last ten years are proof that they are worthy investments for Uganda's developing economy. These are products are both the goods and services that work together with technology.

\section{Uganda age struture}

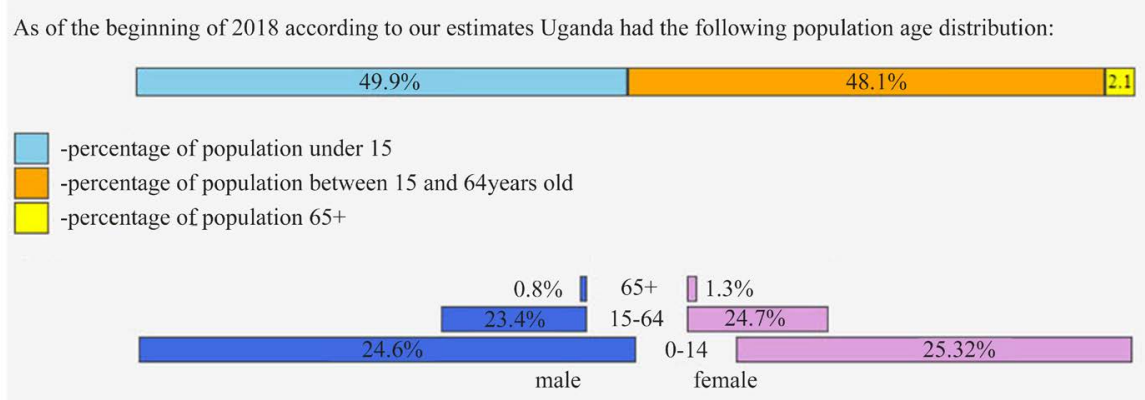

Figure 1. Uganda's age structure 2018 (https://countrymeters.info/en/Uganda).

\section{China age struture}

As of the beginning of 2018 according to our estimates China had the following population age distribution:

\begin{tabular}{|l|c|c|}
\hline $17.6 \%$ & $73.6 \%$ & $8.9 \%$ \\
\hline
\end{tabular}

-percentage of population under 15

-percentage of population between 15 and 64years old

-percentage of population $65+$

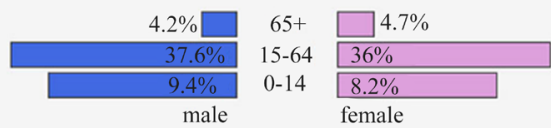

Figure 2. China's age structure 2018 (https://countrymeters.info/en/China). 


\subsection{Solar Energy}

Some of the solar energy products in Uganda include lights, televisions, decoders, radios, fridges, hair clippers, batteries and panels. These imports mostly from China are sold in various sizes and voltages making them flexible to install in homes and small businesses in Kampala city, towns and villages. A rural countrywide solar energy project was started in the year 2011 by a Dutch company called "Solar Now" was launched to plug the loopholes of irregular or no electricity. This company has currently installed solar electricity in sixty-three locations countrywide. It basically installs solar panels on house rooftops and wires up the house with solar lights. These lights use compact florescent and light emitting diode bulbs (30 - 15 Watts) that consume less electricity than the incandescent (100 Watts) bulbs.

Their light radiance is stronger than that of the rural "tadoba" (hand-held kerosene lamp) that is dim, damages eyes and emits toxic smoke. Solar electricity is popular amongst rural school children because they do homework at night without straining their eyes and getting burnt. Inhalation from the "tadoba" kerosene emissions causes lung related diseases (cancer, emphysema).

"Solar Now" also replaces noisy expensive fuel generators that run on diesel or petrol. This means that fossil fuel consumption is reduced, hence saving the environment and reducing overhead costs for small and medium enterprises (SMEs).

Other solar products like the TVs, decoders, fridges and hair clippers have created SMEs in remote areas and small towns. Barber shops and sports bars have sprung up in the countryside. Other solar electricity-based businesses like phone charging ports and mobile money transfers are growing [1].

\subsection{SafeBoda Motorcycle Taxis}

The "Boda bodas" or "bodas" are motorcycle taxis found in the capital city, towns and villages. Boda riders are predominantly young men whose ages range from 16 - 25 years. Before Safe Boda/Taxify/Uber, bodas' reckless driving caused $40 \%$ of national road accidents and charged irregular or expensive fees. They are however popular because they are cheap, fast on the road and can make their way through thick traffic jams. Safe Boda/Taxify/Uber that all started in 2014 by Ugandan and French entrepreneurs, have reduced automobile accidents by creating phone apps that can track the rider and passenger, pick-up points and destinations.

SafeBoda has the most successful motorcycle taxi mobile because it has integrated phone application technology as part of its service. This app has regulated and discounted cash-free/electronic mode of payment. It reduces the discomfort of looking of change (light cash) that is a common reason for disputes. This e-money system has created savings and loan schemes amongst the bodas and in the company. It currently boasts of working with 8200 riders out of the 80,000.

SafeBodas are trained by the traffic police about traffic laws, motorcycle maintenance and first aid response. They have serial numbers on their orange helmets and bibs. Their bibs and the app display their names too. Before pas- 
sengers start their journeys, they are issued helmets and nets for safety and hygiene. They are changing the misconception that all bodas are reckless and dangerous riders (Figure 3).

Because of its regulated fees and safety, SafeBoda riders partner with local companies and individuals on mutual pricing and distance services, causing businesses and professionalism to flourish. The app allows passengers to rate the driver s/he hires, making it very popular as the feedback alerts the company of the bodas' services. It plans to expand in other African cities/big towns like Nairobi, Dar-es Salam and Lagos in 2019.

Uber (American) and Taxify (European) car taxi app companies began hiring and training bodas because they noticed that though SafeBoda has 10\% of Kampala's bodas, this company has expanded quickly both locally and internationally, especially during the years of 2016 to 2018 when the SafeBoda app was upgraded to receive instant feedback [2].

\subsection{Fundi Bots}

The word "fundi" means to "make a product by hand" or artisanship in Swahili. This STEM project was started by a Ugandan enthusiast who teaches school children ( 6 - 15 years) how to build and operate mini robots. This project reduces the gap between theoretical and practical mathematics, technology and engineering. This is an ideal project for product design because it is introduced at primary and ordinary-level secondary school when children's minds are open to invention and innovation. These lessons give students "work experience" long before being employed. It also teaches young minds on how to become job creators and job seekers through technological and engineering innovation (Figure 4).

Since its inception in 2011, Fundi Bots claims to have taught 4500 students

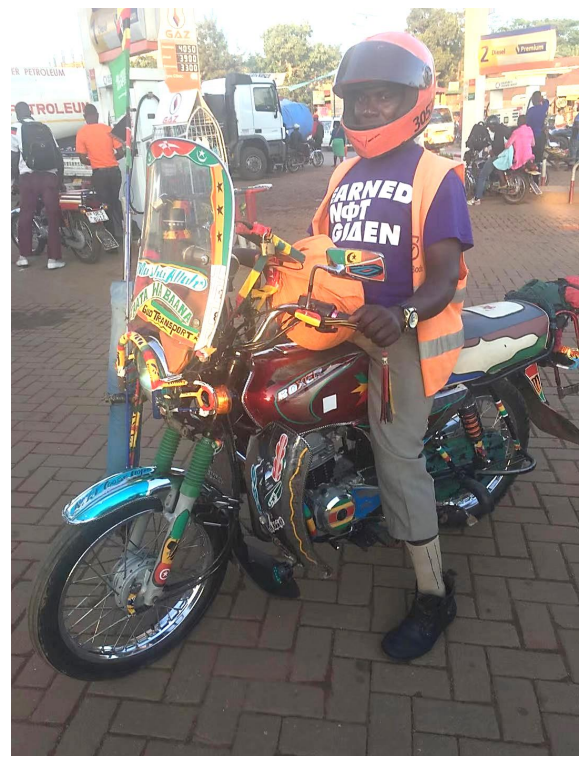

Figure 3. A SafeBoda in his "pimped out ride" in Kampala (Juliet Kategaya Nsiima). 


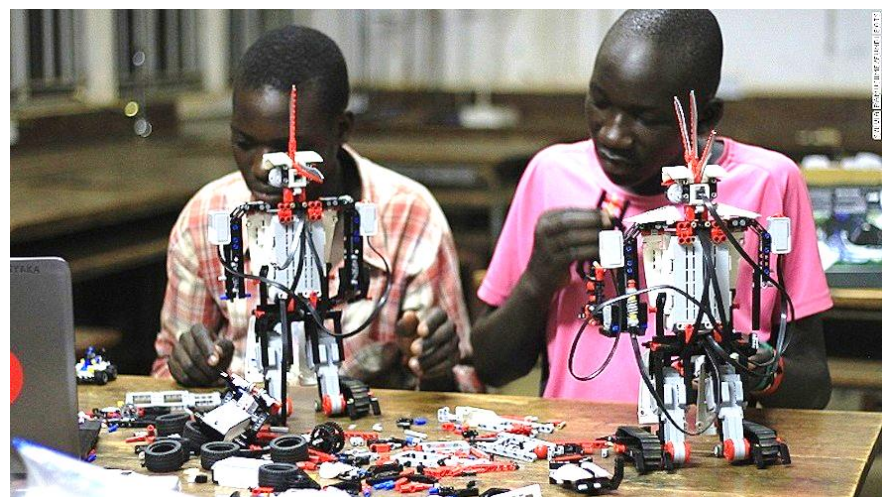

Figure 4. Students make robots at a Fundi Bots workshop in Uganda (https://edition.cnn.com/2015/01/19/tech/fundi-bots-robots-uganda/index.html).

and has created a girl-child program called Fundi Girls whereby parents are encouraged allow their daughters to learn robotics technology. This initiative is urgently needed sine Uganda's young population is mostly unemployed [3].

\subsection{Reusable Sanitary Towels}

Teenage girls living in rural areas and low-income townships are forced to skip school for approximately a week per month because of their menstrual periods. Three other reasons for this are that girls get teased at school by boys when they show signs like menstrual cramps or leakage, their parents marry them off when they start their periods and thirdly, they are "miseducated" that menstrual cramps are reduced by having sex. 2.3 out of 10 schoolgirls drop out of school and many working women skip work because of this biological function that should be celebrated not shamed.

Materials like leaves, old pieces of clothes, pieces of foam are used by rural girls and women to stop menstrual leakages because disposable pads are expensive and/or unavailable. They are unsanitary and cause infections.

Pit latrines are poorly constructed and do not cater for girls and women's needs when changing and disposing pads. There is no table, available water nor sanitary carry bags or bins to clean after oneself. Girls-only latrines in village school are rarely available.

Reusable sanitary towels are one solution to these challenges. AFRI pads Menstrual Kits Uganda claims to be the current leading distributor in the country. Designed by a Canadian couple in 2009, the kit that includes three cotton max pads, one cotton super-max pad and changing bag that can be used for approximately a year. They claim to have sold 2.3 million kits in Uganda since 2010 and have employed 150 people whereby $90 \%$ are women [4].

\subsection{Bloodless Malaria Test Kits}

The medical procedure of pricking one's finger or drawing blood from a vein to test for malaria and other blood identifying pathogens will in the future be replaced by shining a laser light onto the patient's finger. A Ugandan university 
student invented a technological kit called "Matibabu" (means treatment in Swahili) in 2014 that uses a red laser beam that detects the colour, shape and concentration of red blood cells. This detection will determine normal from diseased/infected red blood cells from the malaria parasites attacks. This invention is at its trial stages and plans are on the way to distribute these kits in Africa where 216 million people suffer from malaria at a reasonable price. This kit will reduce patients and medical staff's stress who want this medical procedure to be as painless as possible [5].

\section{Challenges and Proposed Solutions for Product Designers in Uganda}

\subsection{Poor Education or "Miseducation"}

We, Ugandans, are taught to become employees dependent on their salaries instead of innovative entrepreneurs. Most of our families do not teach personal finance skills. Neither do our schools. Instead we are encouraged to be political activists and expensive showmen, wasting time and money that could be better used on financial growth, technological awareness, market penetration and expansion. Countries like China, Japan and Norway are examples of self-sustaining economies because personal finance, health and public management are informally and formally taught to their youth. About $50 \%$ of Chinese products are consumed in China and 70\% of the products consumed in Japan are Japanese [6]. Local innovators and inventors often take personal financial risks and make risky partnerships to design, produce and distribute their products. Few public schools are equipped to encourage critical thinking, experimentation, research and development.

\subsection{Inadequate and Few Ugandan Incubation Hubs}

Incubation hubs are the heart of product design development in the fields of technology and market advancement. It is necessary because of the constant changes in industrial and technological breakthroughs and market trend in Uganda around the world. Expensive research and development projects are difficult to maintain and upgrade without government subsidisation or company sponsorships.

For example, parabolic solar stoves that reduce deforestation are rarely used in Uganda even though the materials are inexpensive and accessible in hardware stores. Parabolic reflectors are made of mirrors, tin foil, or aluminum. They surround a mounted stove or kettle in the hot sunshine. The parabolic reflectors rise temperatures to $150^{\circ} \mathrm{F} / 80^{\circ} \mathrm{C}$ that boils water and cooks food safely. This product was introduced to rural China and India through incubation hubs. They were designed for and distributed to people living in arid and semi-arid areas where trees are scarce but sunlight and heat are plenty.

The good news is that industrial parks are springing up, courtesy of the Uganda Science and Technology Ministry. The Uganda Industrial Research In- 
stitute in Kampala city is a state-owned company that experiments on bamboo, cotton textile and other industrial technology/products. This institute borrows Asian and Western technology and adapts it for local demands. More industrial parks are urgently needed in major towns around the country because different towns have their own technological and industrial challenges.

\subsection{Emergency/Urgency Is the Driving Force for Innovation in Uganda, Not Planning and Competition}

Emergencies and urgencies cause inconsistencies and accidents in product design and development. This emergency/urgency habit compromises the full exploitation and development of local innovation and invention. Regular (annual, bi-annual) science, engineering and technological competitions should be held all over the country. These competitions will encourage innovators to design their products according to market demands, pricing, placement and environmental preservation. These competitions also entice technological companies to invest in better and future technology [7].

\subsection{Poor Hospital Transportation}

Uganda's rural sector is plagued by poor infrastructure especially roads and bridges. Hospital ambulances cannot pick up and drop off patients in emergency situations so they are carried on their relatives' backs or on makeshift stretchers. One solution to this problem is the "boda" ambulance. A motorcycle is attached to a two-wheeled trailer or a two-wheeled medical bed that is used to ferry patients safely and quickly. This product was designed in Guinea, West Africa. Guinea like Uganda has hospitals in the city and towns that ambulances can easily reach. Sick people stuck deep in the villages of Guinea are now picked up and dropped home more frequently because these boda ambulances are price-friendly and can make their way through disused and dangerous village roads and paths [8].

\subsection{Few Industrial Parks}

The good news is that industrial parks are springing up, courtesy of the Science and Technology ministry. In Kampala, we have the Uganda Industrial Research Institute in Kampala city that is state-owned company that experiments on bamboo, cotton textile and other industrial technology/products. But there are the industrial parks in the other 126 districts of the country.

More industrial parks are urgently needed because different districts have their own technological and industrial challenges. These industrial parks link different but interrelated technological and innovative sectors that determine the success or failure of new products. These sectors include research and development, investment, pricing, quality control and environmental protection [9].

\subsection{Inadequate Support Systems for Industrialization and Distribution of Products}

Government bureaucracy delay and deny adequate infrastructure, technology, fac- 
tories, legal affairs matters and distribution opportunities to inventors/innovators.

However, this bureaucracy can be changed by the government and local sponsors creating standardised product design systems. This way, products are tested, categorised and tracked by their key characteristics and their impact on societies into coordinated data banks. Regular support for local products (government or private) through these tracking systems and upgrades will ensure that expensive products will eventually become price-friendly or substitutes are created to accommodate the low-income earners. It will also revise and eliminate sub-standard products that may harm people and the environment [10].

\subsection{Distribution of Poor Quality Products in Uganda}

Ugandans do not have confidence in some of their local products because they consume the low-end products like that of coffee, tea and cotton. If the middle and high income working classes were given the chance to use the good quality local coffee or cotton, they would be able to appreciate and market them.

This can be realised by installing a Product Service Value System (PSVS) to better understand what the consumers' wants are and how a product adds value to their lives on usage, lifestyle and cultural levels (Figure 5). PSVS starts with a survey to determine what consumers in the four economic classes want out of a product(s). The four classes are low end income, lower middle income, higher middle income and high end income classes. Below is an illustration of the process [11].

\subsection{Dumping of Sub-Standard Products by Donor Countries}

Rejected, outdated and used Western and Chinese products have flooded the

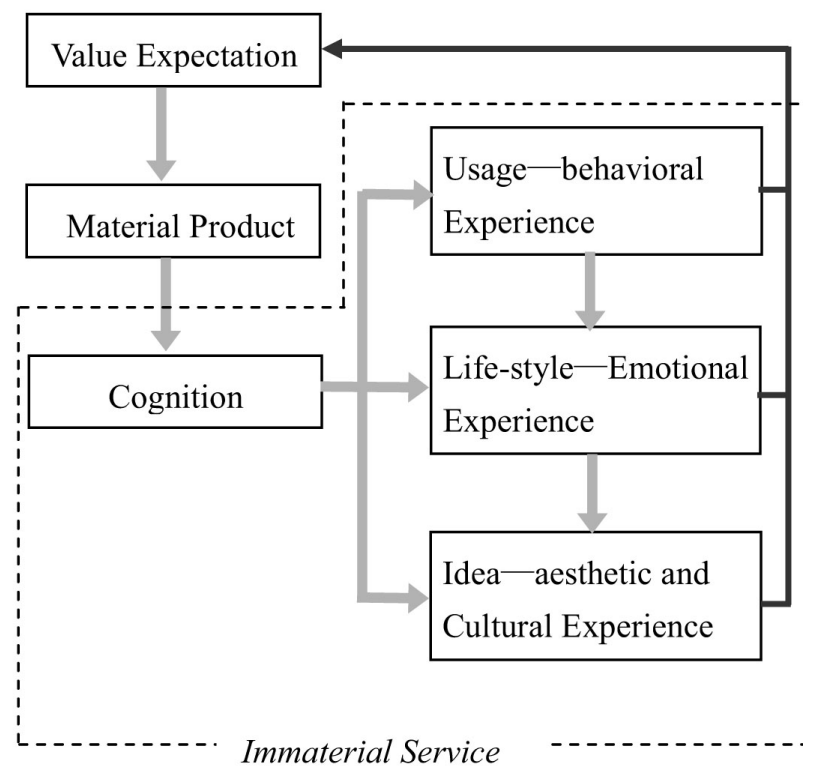

Figure 5. Product Services Process (Na Cheng-ai, Wu Zhi-jun, Xing Jiang-hao (2009). Creative Design Based on Product Service Value System. IEEE Industrial Design Center of Electromechanical Product, Jiangnan University https://ieeexplore.ieee.org/document/5375077). 
Ugandan markets. The most common are textiles, shoes and electronics. They are cheap and hazardous/toxic to the users and environment. They also destroy local industries manufacturing similar products because of their cheap prices. These cheap products have encouraged Ugandan business persons to buy in bulk and sell cheaply, adding to the strain on the local industries are wrestling with donors.

One solution is to renegotiate the African Growth Opportunity Act (AGOA) treaty. It currently allows second hand clothes and shoes from the US to enter East Africa tax-free claiming that they are for humanitarian and emergency purposes. Needless to say, many local non-government and foreign based charity organisations are doing business under the disguise of helping the needy and disadvantaged.

Secondly, systematically phasing out these cheap and dangerous products may start up family and community based cottage industries that can make better and affordable substitute products. Uganda and East African start off by producing simple garments like underwear, vests, socks and brassieres strictly for local consumption and later for exportation, not vice versa.

\section{Conclusions}

Uganda is a developing nation that has the potential to enrich its people, the youth in particular, job creators and not job seekers who can improve their economies directly and the country on a macro level. With only $2 \%$ of the population being 65 years and above, the youth do not have the luxury of waiting for jobs upon completion of education. They need to create them as they study. This in turn means that their education systems at home and in school need to restructure their systems.

Uganda is one African country with a plethora of natural resources that can be exploited to improve the economy if different macro- and micro-systems work in harmony. It is evident that Uganda has not fully grasped that product designers need to work with other influences and systems in order for them to thrive. When she does, more home-grown innovations and inventions will spring up and flourish.

Some innovators and inventors are working with investors, industrialists, marketers and government for support and protection. These initiatives will pull Uganda out of poverty to self-sustenance and prosperity.

\section{Acknowledgements}

Salutations go to my study supervisors, Professors Fang Xing and Lv Jiefeng for their guidance through this publication process. Salutations also go to my Proverbs 31 aunts who opened doors for my PhD education.

\section{Conflicts of Interest}

The authors declare no conflicts of interest regarding the publication of this paper. 


\section{References}

[1] https://www.solarnow.eu

[2] https://www.safeboda.com/home

[3] http://fundibots.org/

[4] https://www.afripads.com/our-products/

[5] https://www.bbc.com/news/world-africa-44481723

[6] Ma, D.B. (2005) Between Cottage and Factory: Evolution of Chinese and Japanese Silk-Reelimg Industries in the Latter Half of the Nineteenth Century. Journal of Asia Pacific Economy, 10, 195-213. https://doi.org/10.1080/13547860500071451 http://personal.lse.ac.uk/mad1/ma_pdf_files/between $\% 20$ cottage $\% 20$ and\%20factory .pdf

[7] Shindi, U.E. (2005) Designing Concepts of Products for Sustainable Consumption (3). IEEE Laboratory of Sustainable and Universal Design (LSUD). https://ieeexplore.ieee.org/document/1619372

[8] https://www.unicef.org/childsurvival/index_50063.html

[9] Saleh, B., Sattar, R.M. and Mohd, A.H. (2018) The Conceptual Framework of Quality Product Design Based on Computer-Aided Design (CAD). Creative Education, 9, 2311-2324. https://doi.org/10.4236/ce.2018.914171 https://www.scirp.org/journal/PaperInformation.aspx?PaperID=88165

[10] Du, W., Mo, R. and Li, S. (2011) Key Characteristics Extraction Method in Product Concept Design. IEEE Northwestern Polytechnic University, Xi'an Shaanxi. https://ieeexplore.ieee.org/document/6182406

[11] Na, C.A., Wu, Z.J. and Xing, J.H. (2009) Creative Design Based on Product Service Value System. IEEE Industrial Design Center of Electromechanical Product, Jiangnan University. https://ieeexplore.ieee.org/document/5375077 https://doi.org/10.1109/caidcd.2009.5375077 